\title{
Silica/Titania Graphite Composite Modified with Chitosan and Tyrosinase Employed as a Sensitive Biosensor for Phenolic Compounds
}

\author{
Marina T. Laranjo, ${ }^{a}$ Franciele M. Morawski, ${ }^{a}$ Silvio L. P. Dias, ${ }^{a}$ Edilson V. Benvenutti, ${ }^{a}$ \\ Leliz T. Arenas ${ }^{a}$ and Tania M. H. Costa ${ }^{\circledR} * a$ \\ ${ }^{a}$ Laboratório de Sólidos e Superfícies (LSS), Instituto de Química, \\ Universidade Federal do Rio Grande do Sul (UFRGS), \\ CP 15003, 91501-970 Porto Alegre-RS, Brazil
}

\begin{abstract}
A mesoporous, high surface area and conductive silica/titania graphite composite modified with chitosan and functionalized with tyrosinase was prepared. The composite was obtained by the sol-gel method and the surface of the resultant material was modified with chitosan solutions containing 5,10 and $15 \%$ by mass. The textural characterization showed that even after modification with chitosan, the composite maintains a pore volume near $0.70 \mathrm{~cm}^{3} \mathrm{~g}^{-1}$ and pore diameter between 10 and $50 \mathrm{~nm}$, adequate for enzyme immobilization. The tyrosinase was immobilized on the composite that was modified with $5 \%$ chitosan solution. A carbon ceramic electrode was manufactured with this material and was used as an electrochemical biosensor for phenolic compounds, showing low detection limits in the linear range from 40 to $350 \mu \mathrm{mol} \mathrm{\textrm {L } ^ { - 1 }}$ and good sensitivity of $0.284,0.141$ and $0.165 \mu \mathrm{A} \mathrm{mol}^{-1} \mathrm{~L}$ for catechol, dopamine and pyrogallol, respectively. In this composite the enzyme showed to be operative and stable after several months.
\end{abstract}

Keywords: sol-gel, cyclic voltammetry, chronoamperometry, electrochemical biosensor, enzyme immobilization

\section{Introduction}

Phenolic compounds have been widely used in different industrial products in the medical and food fields, and their determination is very important for the quality and control of these products. Different methods have been reported for the analysis of phenolic compounds, such as high performance liquid chromatography (HPLC), ${ }^{1}$ solid phase extraction ${ }^{2}$ and electrochemical methods. ${ }^{3}$ The electrochemical methods have proven to be a great alternative for developing adequate sensors for phenolic compounds due to their fast response and low cost. ${ }^{4}$ However, to obtain excellent responses using simple systems has been a challenge in this field, and researchers have focused on trying to optimize electrochemical procedures by finding different types of working electrodes, such as carbon paste, ${ }^{5}$ glassy carbon, ${ }^{6}$ imprinted $^{7}$ and carbon ceramic. ${ }^{8}$

Electrochemical biosensors based on the tyrosinase enzyme have been highlighted due to the specificity and selectivity of this enzyme for phenolic compounds. ${ }^{910}$ The

*e-mail: taniaha@iq.ufrgs.br stability of tyrosinase enzyme has been reported to be an important property in this type of biosensor. However, tyrosinase is an unstable enzyme, and hard work is still necessary to develop appropriate support matrices to guarantee the operational stability of the enzyme in the biosensors. ${ }^{11}$ The focus of recent studies is to obtain new matrices with textural properties, such as a high surface area and large pores to immobilize the enzyme, maintaining its mobility and activity with the aim of preparing efficient and sensible electrodes. ${ }^{4}$

Silica-based carbon ceramic electrodes are a good choice considering their simplicity, low cost and easy production. These carbon ceramic composites can be synthetized by sol-gel method through the hydrolysis and polycondensation of silicate precursors, where graphite or another carbonbased conductive matrix is incorporated. This method allows compounds to be obtained that are homogeneously dispersed with controlled porosity. Planning the textural properties, such as a high specific surface and adequate pore size is a very important task. These properties allow the immobilization of macromolecules, thus making these composites suitable for the manufacturing of adequate electrodes. ${ }^{12,13}$ To enhance the performance of carbon ceramic 
electrodes, the incorporation of other metal oxides has been used, with the goal of decreasing the electrical resistance of the silica matrix. ${ }^{14}$ Silica/titania graphite composites present mechanical and chemical stability and can be a good choice to prepare this type of electrode, however, this material has rarely been applied..$^{15}$ One important advantage of this material is related to the $\mathrm{TiO}_{2}$ Lewis acidity feature that allows covalent reaction with the basic nitrogen atom of $\mathrm{NH}_{2}$ groups, permitting its functionalization with different organic compounds, such as chitosan. ${ }^{16}$

As already reported, ${ }^{17}$ the biocompatibility of chitosan can enhance the stability and activity of enzymes immobilized on inorganic supports, maintaining its mobility. Therefore, the development of a carbon ceramic conductor material containing chitosan is of interest because it could be an excellent support for the immobilization of tyrosinase, with the goal of using it as an electrochemical biosensor for the determination of phenolic compounds. Such a new material has not yet been reported.

Herein the synthesis of conductive silica/titania graphite ( $\mathrm{Si} / \mathrm{Ti}-\mathrm{G})$ composite by the sol-gel method with a large surface area and controlled porosity is proposed, in which the effect of different amounts of chitosan added was studied. The tyrosinase was immobilized on the surface of the composite and then employed as a carbon ceramic electrode (CCE). This electrode was also tested, using cyclic voltammetry, chronoamperometry and electrochemical impedance spectroscopy as an electrochemical biosensor for catechol, pyrogallol and dopamine.

\section{Experimental}

\section{Reagents}

Tetraethyl orthosilicate (TEOS) (Aldrich, Shangai, China, 98\%), titanium(IV) isopropoxide (TIPOT) (Aldrich, Shangai, China, 97\%), ethanol (Merck, Darmstadt, Germany, 99.9\%), hydrofluoric acid (HF) (Merck, Darmstadt, Germany, 40\%), hydrochloric acid $(\mathrm{HCl})$ (Merck, Darmstadt, Germany, 37\%), tyrosinase (Ty) (Sigma, St. Louis, USA, E.C. 1.14.18.1 with an activity of $1000 \mathrm{U} \mathrm{mg}^{-1}$, in this product the quantity of protein is $25 \%$ by weight), pyrogallol (Riedel de Häen, Seelze, Germany, 99\%), catechol (Sigma Aldrich, Seelze, Germany, 99\%), dopamine (Sigma, Seelze, Germany, 98\%), graphite powder (Sigma-Aldrich, St. Louis, USA, 99.99\%), chitosan (Aldrich, Shangai, China), glutaraldehyde solution (Sigma Aldrich, St. Louis, USA, 25\% in water), and potassium chloride (Sigma Aldrich, Seelze, Germany, 99\%), all of analytical grade, were used without previous purification. Phosphate buffer solution (PBS) $\left(0.1 \mathrm{~mol} \mathrm{~L}^{-1}, \mathrm{pH}=7.0\right)$ was prepared from $\mathrm{NaH}_{2} \mathrm{PO}_{4}$ (F Maia, São Paulo, Brazil, 98\%) and $\mathrm{Na}_{2} \mathrm{HPO}_{4}$ (F Maia, São Paulo, Brazil, 99\%). Caffeine (Delaware, Pennsylvania, USA), anhydrous glucose (p.a. Carlo Erba, São Paulo, Brazil), citric acid monohydrate (Synth, São Paulo, Brazil), ascorbic acid (Synth, São Paulo, Brazil), and uric acid (Aldrich, São Paulo, Brazil) were also utilized. All solutions were prepared in distilled water.

\section{Synthesis of the silica/titania graphite composite}

The silica/titania graphite $(\mathrm{Si} / \mathrm{Ti}-\mathrm{G})$ carbon ceramic material was synthesized by a sol-gel method according to the following procedure: first, a pre-hydrolysis of TEOS was performed, where $5 \mathrm{~mL}$ of TEOS was dissolved in $7 \mathrm{~mL}$ of ethanol. Then, $1.6 \mathrm{~mL}$ of distilled water and $0.4 \mathrm{~mL}$ of $\mathrm{HCl}(37 \%)$ were added. The solution was kept under magnetic stirring for $1 \mathrm{~h}$. After that, $2 \mathrm{~mL}$ of TIPOT was added to this solution and submitted to an ultrasonic bath for $5 \mathrm{~min}$. Thereafter, $0.94 \mathrm{~g}$ of powdered graphite was added under magnetic stirring and again submitted to an ultrasonic bath for $1 \mathrm{~h}$. In sequence, $\mathrm{HF} / \mathrm{HCl}$ catalyst was added dropwise in a ratio of 2:1 until the gelation of the material. The resulting gel remained at rest for approximately 15 days until complete drying. After this time, the material was crushed and washed with ethanol and water; the resulting solid (nearly $3 \mathrm{~g}$ ) was dried under vacuum at $80{ }^{\circ} \mathrm{C}$ for $2 \mathrm{~h}$.

\section{Preparation of the chitosan Si/Ti-G material}

Three solutions with varied amounts of chitosan were obtained, with 5,10 and $15 \%$ by mass upon addition of 50,100 and $150 \mathrm{mg}$ of chitosan, respectively, to $10 \mathrm{~mL}$ of distilled water and $0.4 \mathrm{~mL}$ of $\mathrm{HF}$, using magnetic stirring for $10 \mathrm{~min}$. In sequence, these solutions were neutralized with $1 \mathrm{~mol} \mathrm{~L}{ }^{-1} \mathrm{NaOH}$ up to a $\mathrm{pH}$ of 6 . Afterwards, $1.00 \mathrm{~g}$ of Si/Ti-G material was added to each chitosan solution, and it remained under mechanical stirring and reflux for $24 \mathrm{~h}$. The materials were washed with water and ethanol, followed by vacuum drying at a temperature of $80{ }^{\circ} \mathrm{C}$, for $2 \mathrm{~h}$. The resulting materials prepared from chitosan solutions containing 5,10 and $15 \%$ by mass were named CS-5, CS-10 and CS-15, respectively. The amount of immobilized chitosan for each sample was estimated by thermogravimetric analysis (TGA).

Immobilization of tyrosinase on the CS-5 material

The CS-5 material was used as a matrix for the immobilization of the tyrosinase enzyme. The CS-5 material $(1.00 \mathrm{~g})$ was first activated with glutaraldehyde 
(Glut) by putting it in contact with $20 \mathrm{~mL}$ of phosphate buffer solution at a $\mathrm{pH}$ of 7 containing $1 \%$ glutaraldehyde. The material remained under mechanical stirring for $5 \mathrm{~h}$. Afterwards, it was washed with phosphate buffer solution and water, followed by vacuum drying at $60{ }^{\circ} \mathrm{C}$. The material was called CS-5-Glut.

In sequence, $1.16 \mathrm{mg} \mathrm{mL}^{-1}$ tyrosinase enzyme (Ty) phosphate buffer solution was prepared, and $5 \mathrm{~mL}$ of this tyrosinase solution was added to $250 \mathrm{mg}$ of the CS-5-Glut material, remaining in contact for $12 \mathrm{~h}$. The material was washed with phosphate buffer at a $\mathrm{pH}$ of 7 and finally vacuum dried at room temperature. This material was called CS-5-Ty.

To estimate the total amount of protein immobilized on the CS-5 support, the Lowry method was used..$^{18}$ This method is based on a mixture containing molybdate, tungstate and phosphoric acid (Folin-Ciocalteau reagent), which is reduced when reacted with proteins in the presence of copper(II), producing a maximum absorption at $750 \mathrm{~nm}$. The equipment used was an Amersham Bioscience Ultraspec 3100 pro spectrophotometer.

\section{Characterization}

$\mathrm{N}_{2}$ adsorption-desorption isotherms were measured at the liquid nitrogen boiling point using Tristar II $3020 \mathrm{Kr}$ Micromeritics equipment. The samples were previously degassed at $60^{\circ} \mathrm{C}$ (except for samples with enzymes, which were degassed at room temperature) under vacuum for $20 \mathrm{~h}$. The specific surface areas were determined by the Brunauer, Emmett and Teller (BET) multipoint technique, and the pore size distribution curves were obtained by using the Barret, Joyner and Halenda (BJH) method. ${ }^{19}$ The thermogravimetric analyses (TGA) were performed using a Shimadzu TGA-50 2 instrument under an argon flow with a heating rate of $20^{\circ} \mathrm{C} \mathrm{min}-1$ from room temperature up to $700^{\circ} \mathrm{C}$.

\section{Electrochemical measurements}

The carbon ceramic electrodes were prepared using $30 \mathrm{mg}$ of comminuted material. They were pressed with a 3 ton force for 3 min using a PIKE Technologies-Crush IR mechanical press. The resulting disks were connected to a glass tube $(10 \mathrm{~cm}$ in length and $6 \mathrm{~mm}$ in diameter). The electrodes were stored in a refrigerator with a temperature of approximately $5{ }^{\circ} \mathrm{C}$ when they were not being used. A copper wire was placed into the glass tube and near $1 \mathrm{~cm}$ was completed with graphite to obtain electrical contact. The electrochemical measurements were performed using a Potentiostat/Galvanostat IviumStat using an electrochemical system composed of three electrodes. A platinum wire was used as the auxiliary electrode, and a saturated calomel electrode (SCE) was used as the reference electrode.

Electrochemical characterization was performed by cyclic voltammetry (CV) in an electrolyte solution consisting of $1.0 \mathrm{mmol} \mathrm{L}^{-1}$ potassium ferricyanide, $1.0 \mathrm{mmol} \mathrm{L}^{-1}$ potassium ferrocyanide and $0.1 \mathrm{~mol} \mathrm{~L}^{-1} \mathrm{KCl}$, in phosphate buffer ( $\mathrm{pH}$ 7.0). For the electrochemical studies of catechol, pyrogallol and dopamine, cyclic voltammetry measurements were obtained in the potential range of -0.6 to $0.8 \mathrm{~V}$. Chronoamperometric analysis was performed at the maximum peak potential estimated for each analyte. These measurements were performed in a $0.1 \mathrm{~mol} \mathrm{~L}^{-1} \mathrm{KCl}$ solution, which was prepared in phosphate buffer at a $\mathrm{pH}$ of 7.0. All measurements were made at ambient conditions, room temperature and atmospheric pressure. Electrochemical impedance spectroscopy (EIS) assays were performed using an AUTOLAB PGSTAT 30/ FRA 2, in the $10 \mathrm{kHz}-10 \mathrm{mHz}$ frequency range with a sinusoidal voltage amplitude of $10 \mathrm{mV}$, in the presence of a potassium ferricyanide and potassium ferrocyanide solution $\left(1.0 \mathrm{mmol} \mathrm{L}^{-1}\right)$ and $\mathrm{KCl}\left(0.1 \mathrm{~mol} \mathrm{~L}^{-1}\right)$ in phosphate buffer at a pH of 7.0, applying half wave potential of $0.22 \mathrm{~V}$.

\section{Results and Discussion}

\section{Characterization of the Si/Ti-G materials}

The silica/titania graphite ceramic composites modified with different amounts of chitosan (CS-5, CS-10 and CS-15 materials) were characterized by nitrogen adsorption/ desorption isotherms, and the results are shown Figure 1.

The isotherm inflexions occur at high $\mathrm{P} / \mathrm{P}_{0}$ values, above 0.8 , with hysteresis typical of mesoporous materials. The

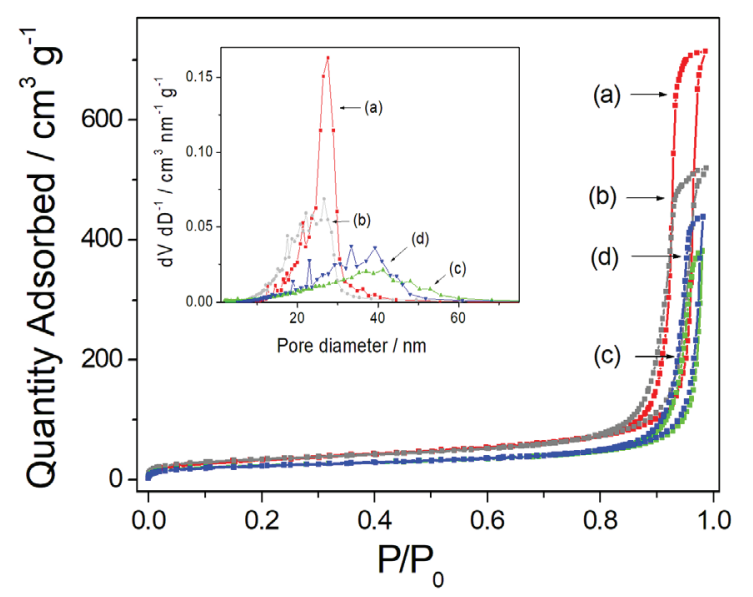

Figure 1. $\mathrm{N}_{2}$ adsorption-desorption isotherms. Inset figure: BJH pore size distribution curves of (a) Si/Ti-G, (b) CS-5, (c) CS-10 and (d) CS15 materials. 
specific surface area and pore volume values are shown in Table 1.

Table 1. Specific surface areas and pore volumes of materials obtained by BET and BJH

\begin{tabular}{lcc}
\hline Material & Surface area $/\left(\mathrm{m}^{2} \mathrm{~g}^{-1}\right)$ & Pore volume $/\left(\mathrm{cm}^{3} \mathrm{~g}^{-1}\right)$ \\
\hline Si/Ti-G & $123 \pm 4$ & $1.10 \pm 0.01$ \\
CS-5 & $119 \pm 4$ & $0.79 \pm 0.01$ \\
CS-10 & $82 \pm 3$ & $0.58 \pm 0.01$ \\
CS-15 & $82 \pm 3$ & $0.67 \pm 0.01$ \\
CS-5-Glut & $119 \pm 6$ & $0.72 \pm 0.03$ \\
CS-5-Ty & $27 \pm 2$ & $0.17 \pm 0.01$ \\
\hline
\end{tabular}

Glut: glutaraldehyde; Ty: tyrosinase.

Compared to a silica/titania matrix, a slight decrease of the surface is observed for CS-5, whereas CS-10 and CS-15 present a much smaller surface area. Furthermore, the fact that samples CS-10 and CS-15 present the same surface area suggests saturation of chitosan on the materials' surface. The pore volume presented a decreasing trend for all chitosan-modified materials. The inset of Figure 1 shows the pore size distribution curves. The Si/Ti-G material presents mesopores in the diameter range from 10 to $33 \mathrm{~nm}$, with a maximum of approximately $27 \mathrm{~nm}$. The curve for the CS-5 material presents pores in the same region, but an evident reduction in the pore volume can be observed. For a large amount of chitosan, such as in the CS-10 and CS-15 materials, the curves show larger pores with a broader distribution between 10 and $50 \mathrm{~nm}$, along with a marked reduction in the pore volume when compared to the Si/Ti-G material. Thus, it was possible to obtain silica/ titania materials grafted with varied amounts of chitosan that presented interesting textural properties, such as an elevated surface area and pore volume as well as a large pore size to allow the immobilization of macromolecules, such as enzymes.

Using the thermogravimetric curves, it was possible to estimate the amount of chitosan immobilized on the materials. The curves are shown in Figure 2, and the estimated values in each temperature range are shown in Table S1 in the Supplementary Information (SI) section. The inset of Figure 2 shows the curve of chitosan for comparison.

The curves show the weight loss values in different temperature ranges. The first weight loss below $150{ }^{\circ} \mathrm{C}$ is observed due to the adsorbed water. The second weight loss between 150 and $400{ }^{\circ} \mathrm{C}$ is due to the desorption and decomposition of CS, as can be seen in the inset of Figure 2 for chitosan. In this temperature range, the dehydroxylation of silica and titania were also observed.

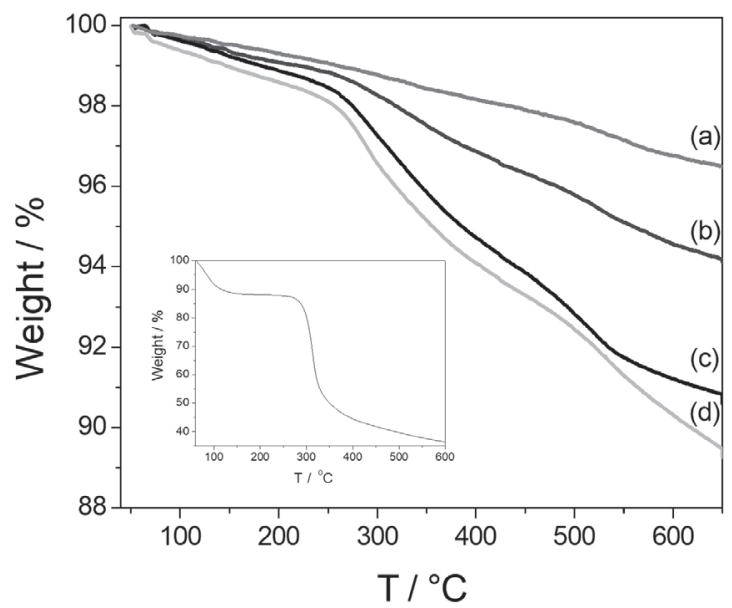

Figure 2. Thermogravimetric curves of (a) Si/Ti-G, (b) CS-5, (c) CS-10 and (d) CS-15 materials. Inset figure: thermogravimetric curve of chitosan.

This weight loss for the CS-5 material is more pronounced in relation to that of the Si/Ti-G material, indicating the presence of a higher organic content (2.5\%). Comparing the thermogravimetric curves of the CS-10 and CS- 15 materials in the same temperature range, similar losses of 4.5 and $4.9 \%$ were observed, even though a higher proportion of chitosan was added during the synthesis of the CS-15 material. This result can be attributed to the fact that the surface of the Si/Ti-G material used for the immobilization of chitosan reaches saturation with the addition of $10 \%$ chitosan. These results agree with the textural analysis, which showed chitosan surface saturation for the CS-10 and CS- 15 samples.

The electrochemical behavior of all the synthetized materials was studied by $\mathrm{CV}$ using a carbon ceramic electrode. Figure 3 shows the CV curves of Si/Ti-G, CS-5, CS-10 and CS-15 materials performed in a $1 \mathrm{mmol} \mathrm{L}^{-1}$ $\mathrm{K}_{3}\left[\mathrm{Fe}(\mathrm{CN})_{6}\right] / \mathrm{K}_{4}\left[\mathrm{Fe}(\mathrm{CN})_{6}\right]$ solution.

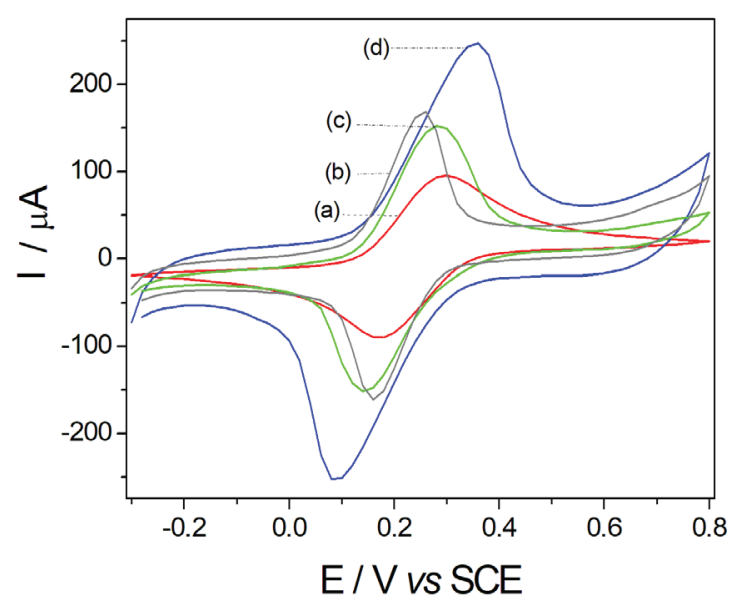

Figure 3. Cyclic voltammetry of the carbon ceramic electrodes (a) Si/Ti-G, (b) CS-5, (c) CS-10 and (d) CS-15 performed at a scan rate of $20 \mathrm{mV} \mathrm{s}^{-1}$ in the presence of a $1.0 \mathrm{mmol} \mathrm{L}^{-1} \mathrm{~K}_{3}\left[\mathrm{Fe}(\mathrm{CN})_{6}\right] / \mathrm{K}_{4}\left[\mathrm{Fe}(\mathrm{CN})_{6}\right]$ solution. 
The CV curve for the Si/Ti-G matrix presents welldefined redox peaks. The electroactive area of this electrode was estimated using the Randles-Sevcik equation as $0.98 \mathrm{~cm}^{2}$ by equation $1: 20$

$\mathrm{I}_{\mathrm{p}}=2.69 \times 10^{5} \times \mathrm{n}^{3 / 2} \times \mathrm{A} \times \mathrm{D}_{0} \times \mathrm{C} \times \mathrm{v}^{1 / 2}$

where Ip is the peak current, $\mathrm{n}$ is the number of transferred electrons in the redox process $(n=1), A$ is the electroactive area, $\mathrm{D}_{0}$ is the diffusion coefficient ${ }^{21}$ of $6.70 \times 10^{-6} \mathrm{~cm}^{3} \mathrm{~s}^{-1}$, $\mathrm{C}$ is the concentration $\left(1.0 \times 10^{-6} \mathrm{~mol} \mathrm{~cm}^{-3}\right)$ and $\mathrm{v}$ is the scan rate.

The CV curves for CS-5, CS-10 and CS-15 materials also present defined redox peaks, and it was possible calculate the electrochemical parameters shown in Table 2, including the difference between the cathodic and anodic peak potentials $\left(\Delta \mathrm{E}_{\mathrm{p}}\right)$, anodic peak current $\left(\mathrm{I}_{\mathrm{pa}}\right)$, and cathodic peak current $\left(I_{p c}\right)$. These parameters allowed the best electrochemical behavior to be determined.

Considering the $\mathrm{I}_{\mathrm{pa}} / \mathrm{I}_{\mathrm{pc}}$ peak relationship, which is one important factor to evaluate the reversibility of a redox couple, the ratios were very close to 1 for all materials, which is indicative of electrochemically reversible systems. However, using the criterion of $\Delta \mathrm{E}_{\mathrm{p}}$, which evaluates the reversibility considering the resistance to electron transfer, the obtained values were higher than the ideal value of $59 \mathrm{mV}$, indicating that the redox couple process is quasi-reversible. ${ }^{20-22}$ For the Si/Ti-G, the $\Delta \mathrm{E}_{\mathrm{p}}$ was $118 \mathrm{mV}$, which is higher than that of CS-5, which was $99 \mathrm{mV}$. This is the lowest value for $\Delta \mathrm{E}_{\mathrm{p}}$ among all of the samples. It was reported in the literature ${ }^{23}$ that the incorporation of organic content in the electrodes produces difficulty in electron transfer and increases the $\Delta \mathrm{E}_{\mathrm{p}}$; however, for the CS-5 electrode the small amount of organic incorporation did not produced this effect. On the other hand, when larger quantities of chitosan were added, an increase in the resistance to the electron transfer was clearly indicated for the CS-10 and CS-15 materials, which presented $\Delta \mathrm{E}_{\mathrm{p}}$ values of 141 and $269 \mathrm{mV}$, respectively. Table 2 also shows the increase in the peak current values obtained for all materials after the incorporation of chitosan. This increase can be related to the possible adsorption of $\left[\mathrm{Fe}(\mathrm{CN})_{6}\right]^{3-} /\left[\mathrm{Fe}(\mathrm{CN})_{6}\right]^{4-}$ probe on the chitosan surface. It has been reported that protonated amino groups can adsorb negative ions from the $\left[\mathrm{Fe}(\mathrm{CN})_{6}\right]^{3-} /\left[\mathrm{Fe}(\mathrm{CN})_{6}\right]^{4-}$ system, enabling the redox behavior at the surface and therefore increasing the peak current. ${ }^{24}$ This adsorption process can also explain the decrease of the $\Delta \mathrm{E}_{\mathrm{p}}$ values from $118 \mathrm{~V}$ for the SiTi-G to $99 \mathrm{~V}$ for the CS-5 electrode. In the adsorption controlled processes a symmetry in peak shape and position is observed and therefore a very small $\Delta \mathrm{E}_{\mathrm{p}}{ }^{20}$

Comparing the chitosan modified electrodes for the peak-to-peak separation, anodic and cathodic peak current, the CS-5 material showed promising behavior to be used as an electrode because, despite presenting a peak current lower than that of the CS-15 material, it has less resistance to electron transfer $\left(\Delta \mathrm{E}_{\mathrm{p}}=99 \mathrm{mV}\right)$. For a better evaluation, EIS measurements were performed. The EIS is a more complete technique that evaluates at high and low frequencies the polarization, the double electric layer, the charge transfer resistance of the solution, of the electrode in the interface electrode solution as well as the mass transport. Using this technique it is possible to evaluate other aspects of the electrode that were not observed by the CV. The Nyquist diagrams obtained are showed in Figure S1 (SI section). The Table 2 shows the values of charge transfer resistance obtained. The CS-5 material presented a lower resistance value $\left(1600 \Omega \mathrm{cm}^{-2}\right)$ than the CS-10 $\left(2450 \Omega \mathrm{cm}^{-2}\right)$ and CS-15 $\left(2853 \Omega \mathrm{cm}^{-2}\right)$. It was also possible to observe that the $\mathrm{Si} / \mathrm{Ti}-\mathrm{G}$ presented the lowest charge transfer resistance because it not contains chitosan. With the addition of the chitosan an increasing of the charge transfer resistance was observed for the CS-5. In the CV measures for the CS-5 it was not observed due to the adsorption process of the $\left[\mathrm{Fe}(\mathrm{CN})_{6}\right]^{3-} /\left[\mathrm{Fe}(\mathrm{CN})_{6}\right]^{4-}$ on the chitosan surface. A higher amount of chitosan immobilized in the CS-10 and CS-15 materials made them more resistive. Considering these set of characteristics and also that it is easier to prepare electrodes in the disk form with the CS-5 material due to the lower organic content, the CS-5 material was considered the best choice for the immobilization of tyrosinase and to be applied as an electrochemical biosensor.

Table 2. Parameters obtained by $\mathrm{CV}$ measurements at a scan rate of $20 \mathrm{mV} \mathrm{s}^{-1}$ and EIS measurements in the presence of a $1.0 \mathrm{mmol} \mathrm{L}^{-1}$ $\mathrm{K}_{3}\left[\mathrm{Fe}(\mathrm{CN})_{6}\right] / \mathrm{K}_{4}\left[\mathrm{Fe}(\mathrm{CN})_{6}\right]$ solution

\begin{tabular}{lccccc}
\hline Electrode & $\Delta \mathrm{E}_{\mathrm{p}} / \mathrm{mV}$ & $\mathrm{I}_{\mathrm{pa}} / \mu \mathrm{A}$ & $\mathrm{I}_{\mathrm{pc}} / \mu \mathrm{A}$ & $\mathrm{I}_{\mathrm{pa}} / \mathrm{I}_{\mathrm{pc}}$ & $\mathrm{R}_{1} /\left(\Omega \mathrm{cm}^{-2}\right)$ \\
\hline Si/Ti-G & 118 & 94.96 & -89.53 & 1.06 & 736 \\
CS-5 & 99 & 168.27 & -160.80 & 1.05 & 1600 \\
CS-10 & 141 & 152.21 & -151.24 & 1.01 & 2450 \\
CS-15 & 269 & 246.71 & -251.73 & 0.98 & 2853 \\
\hline
\end{tabular}

$\Delta \mathrm{E}_{\mathrm{p}}$ : difference between the cathodic and anodic peak potentials; $\mathrm{I}_{\mathrm{pa}}$ : anodic peak current; $\mathrm{I}_{\mathrm{pc}}$ : cathodic peak current; $\mathrm{R}_{1}$ : charge transfer resistance. 


\section{Characterization of the CS-5-Ty material}

After studying the electrochemical behavior of CS-5, this material was modified with glutaraldehyde and labelled as CS-5-Glut. Tyrosinase was then immobilized on its surface, and it was renamed as CS-5-Ty. To evaluate these modifications, the materials were characterized by textural analysis, and Figure 4 shows the adsorption-desorption $\mathrm{N}_{2}$ isotherms.

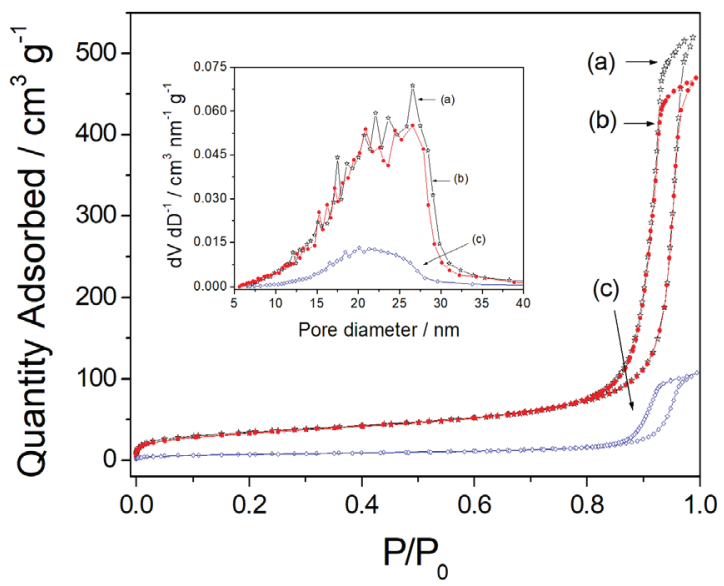

Figure 4. $\mathrm{N}_{2}$ adsorption-desorption isotherms. Inset figure: $\mathrm{BJH}$ pore size distribution curves of (a) CS-5, (b) CS-5-Glut and (c) CS-5-Ty.

It is possible to observe a small decrease in the nitrogen adsorption volume after modification with glutaraldehyde. However, a marked decrease was seen when tyrosinase was incorporated. All materials presented pore size distribution curves with pores in the region between 15 and $30 \mathrm{~nm}$ in diameter (inset of Figure 4); however, the pore density was markedly decreased for the CS-5-Ty.

Table 1 presents the results of the specific surface area and pore volume obtained by the BET and BJH methods, respectively. These values showed that there were not meaningful changes in the specific surface area and pore volume in the first step after modification with glutaraldehyde. However, when the enzyme tyrosinase was immobilized, marked decreases in the specific surface area from 119 to $27 \mathrm{~m}^{2} \mathrm{~g}^{-1}$ and pore volume from 0.72 to $0.17 \mathrm{~cm}^{3} \mathrm{~g}^{-1}$ can be observed. These results prove the effective immobilization of tyrosinase inside mesopores.

The percentage of protein immobilized on the CS-5-Glut material was estimated by using the Lowry protein assay to determine the difference between the added and the residual protein in solution after immobilization. Six milligrams of the commercial product Sigma, containing $1.49 \mathrm{mg}$ of enzyme, was added to a dispersion containing $250 \mathrm{mg}$ of CS-5-Glut material. In this way, $1.49 \mathrm{mg}$ of protein was offered to the CS-5-Glut material, and the residual value found in solution after the immobilization was only
$0.015 \mathrm{mg}$ of protein. Using this result, it was possible to estimate the immobilization efficiency as 99\%. Thus, this material was applied as an electrochemical biosensor for the determination of phenolic compounds.

Electrochemical performance of the CS-5-Ty electrode for phenolic compounds

The carbon ceramic CS-5-Ty electrode was evaluated in the presence of catechol. Figure 5 shows the cyclic voltammograms of the CS-5 and CS-5-Ty electrodes in the absence and presence of $0.157 \mathrm{mmol} \mathrm{L}^{-1}$ catechol for comparison.

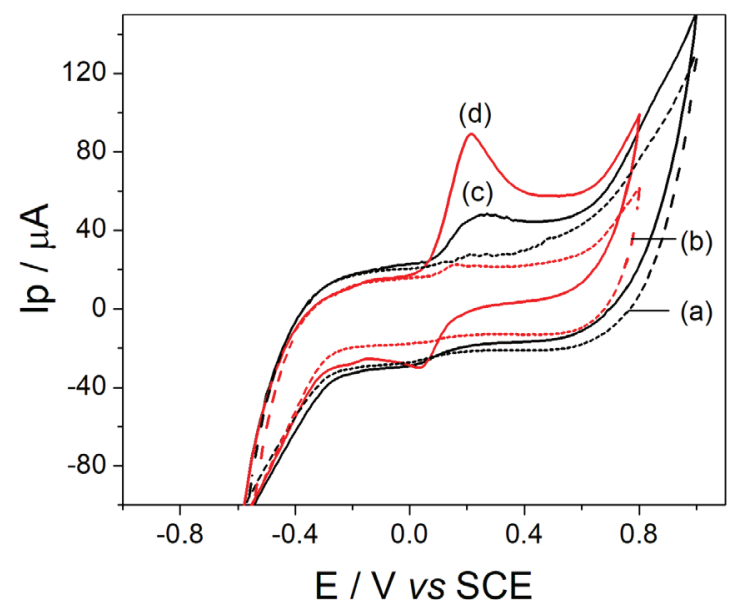

Figure 5. Cyclic voltammograms of the electrodes in phosphate buffer solution at a pH of 7 and $0.1 \mathrm{~mol} \mathrm{~L}^{-1} \mathrm{KCl}$ at $20 \mathrm{mV} \mathrm{s}^{-1}$ : (a) CS-5 and (b) CS-5-Ty in the absence of catechol; (c) CS-5 and (d) CS-5-Ty in the presence of $0.157 \mathrm{mmol} \mathrm{L}^{-1}$ of catechol.

In Figure 5 an anodic peak is observed, which corresponds to oxidation of catechol at $0.23 \mathrm{~V}$ on the CS-5 electrode surface, curve c. When the electrode is modified with tyrosinase (CS-5-Ty, curve d) an impressive increase in the response of the electrode occurs caused by the presence of the enzyme. This result can be explained by the reduction in surface area from 119 to $27 \mathrm{~m}^{2} \mathrm{~g}^{-1}$ (Table 1) and covering of the pores between 10 and $35 \mathrm{~nm}$ (Figure 4), after enzyme immobilization. Therefore, the oxidation of the catechol occurs mainly by the enzyme action, because the surface is almost completely covered by the enzyme. The CV for catechol in the presence of electrode CS-5-Ty presented a half-wave potential $\left(\mathrm{E}_{1 / 2}\right)$ of $0.127 \mathrm{~V}$, which was calculated using equation $2\left(\mathrm{E}_{\mathrm{pa}}\right.$ : anodic peak potential; $\mathrm{E}_{\mathrm{pc}}$ : cathodic peak potential).

$\mathrm{E}_{1 / 2}=\left(\mathrm{E}_{\mathrm{pa}}+\mathrm{E}_{\mathrm{pc}}\right) / 2$

As is known, tyrosinase has a coupled binuclear copper in the active center and presents a mechanism 
involving the oxidation of diphenols in a catalytic cycle to form benzoquinone and water by the equation: catechol + tyrosinase $\left(\mathrm{O}_{2}\right) \rightarrow o$-quinone $+\mathrm{H}_{2} \mathrm{O}$. In this cycle the tyrosinase oxidizes and reduces. In the reduction process two electrons are acquired by two $\mathrm{Cu}^{2+}$ of the active center so producing two $\mathrm{Cu}^{+}$. The reduced form of tyrosinase repairs its activity by transferring the electrons to oxygen and producing water. ${ }^{11,25,26}$ Since this mechanism is $\mathrm{O}_{2}$ concentration-dependent, the measurements were performed in ambient conditions. Considering the well defined anodic-cathodic peaks and mainly the higher anodic peak current obtained for catechol using the CS-5-Ty electrode, (Figure 5), we suggest that the presence of tyrosinase immobilized in this matrix provides electrocatalytic activity in redox reactions of catechol, possibly due to the fast electron transfer from the copper active sites of the enzyme to the electrode. This significant improvement of the electrochemical response indicates that the active sites of the enzyme are operative and available for catechol oxidation. Additionally, the presence of the reduction peak indicates that the $o$-quinone, which is the product of the enzymatic reaction of the catechol oxidation is reduced at potential of $0.05 \mathrm{~V}$ at the electrode surface by the reaction: $o$-quinone $+2 \mathrm{H}^{+}+2 \mathrm{e}^{-} \rightarrow$ catechol..$^{11}$ This catechol is reoxidized in the electrode surface at $0.21 \mathrm{~V}$.

Figure 6a shows the cyclic voltammograms using the CS-5-Ty electrode at different scan rates from 10 to $100 \mathrm{mV} \mathrm{s}^{-1}$ in the presence of $0.157 \mathrm{mmol} \mathrm{L}^{-1}$ catechol. It was observed that the anodic and cathodic peaks shift to higher potential values. This behavior is typical of a quasi-reversible process. ${ }^{20,24,27}$ Figure $6 \mathrm{~b}$ shows that the ratio between the anodic and cathodic peak intensities and the square root of the scan rate presents a linear behavior, which is described by equations 3 and 4 .

$\mathrm{I}_{\mathrm{pa}}(\mu \mathrm{A})=8( \pm 5)+22.7( \pm 0.7) \mathrm{v}^{1 / 2}\left(\mathrm{mV} \mathrm{s}^{-1}\right)^{1 / 2}$ with $\mathrm{R}^{2}=0.995$

$\mathrm{I}_{\mathrm{pc}}(\mu \mathrm{A})=47( \pm 3)-20.1( \pm 0.5) \mathrm{v}^{1 / 2}\left(\mathrm{mV} \mathrm{s}^{-1}\right)^{1 / 2}$

with $\mathrm{R}^{2}=0.998$

This behavior indicates that the process at the electrode interface in the scan rate range studied is diffusioncontrolled. ${ }^{20}$ Considering that some electrodes can present a mixed adsorption/diffusion behavior ${ }^{28}$ and therefore aiming to confirm this diffusional behavior, in Figure 6c the angular coefficient of the ratio between log of the peak current intensity and the log of scan rate was determined to be nearly 0.5 , (equations S1 and S2 of the SI section), confirming that at the interface between the electrode and solution the process is diffusion-controlled.

In general, the titania-containing electrodes present an adsorption controlled process because the titania adsorbs the phenolic compounds. ${ }^{29}$ In the present case, as the behavior was diffusion controlled, we can suggest that the titania surface is completely covered by chitosan, hindering the adsorption of catechol.

The kinetic parameters were evaluated using the Tafel plot. Figure S2 (SI section) presents the cyclic voltammogram of the CS-5-Ty electrode in the presence of $0.385 \mathrm{mmol} \mathrm{L}^{-1}$ of catechol in phosphate buffer solution $(\mathrm{pH} 7)$. Taking into account the rising part of the currentvoltage of this cyclic voltammogram curve at $10 \mathrm{mV} \mathrm{s}^{-1}$, the
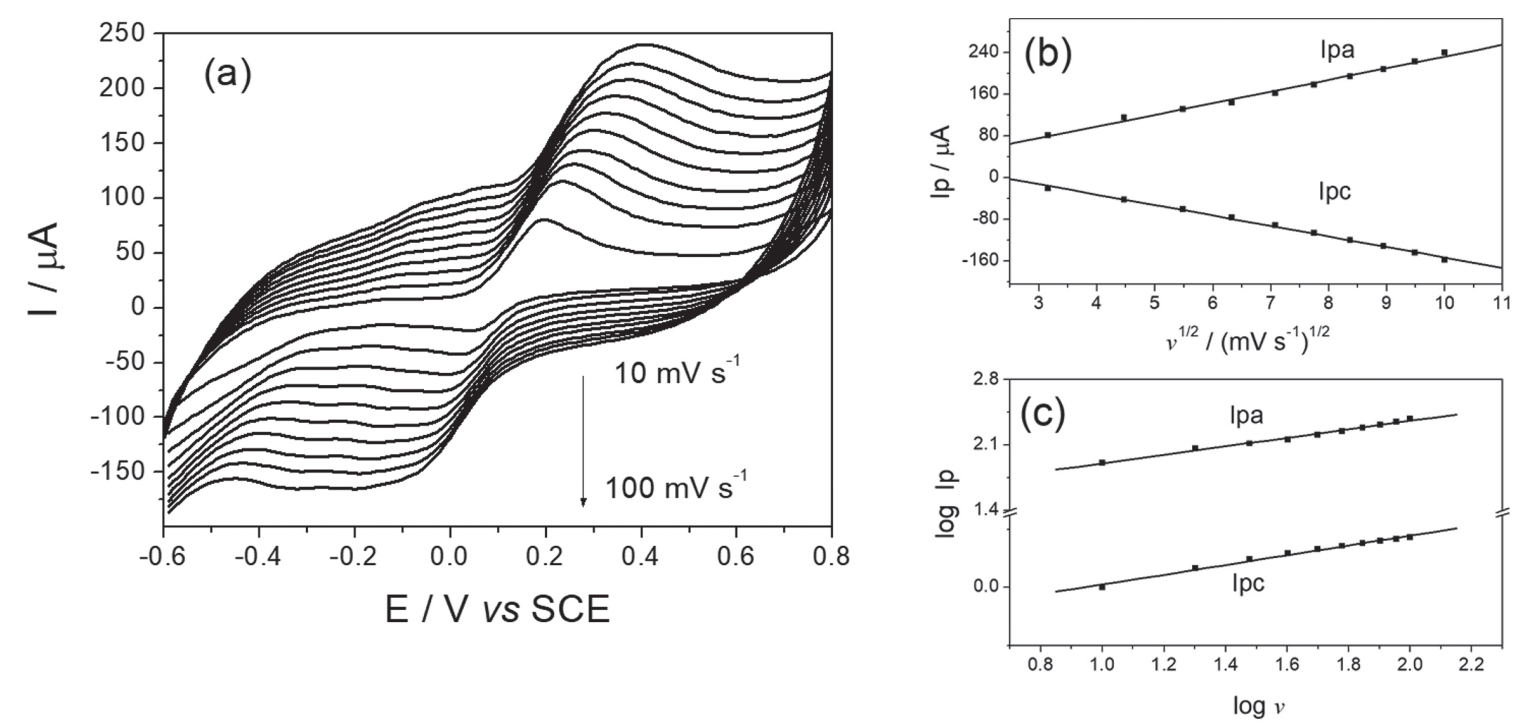

Figure 6. (a) Cyclic voltammograms using the CS-5-Ty electrode at different scan rates from 10 to $100 \mathrm{mV} \mathrm{s}^{-1}$ in the presence of $0.385 \mathrm{mmol} \mathrm{\textrm {L } ^ { - 1 }}$ catechol. (b) Linear relationship between $\mathrm{I}_{\mathrm{pa}}$ and $\mathrm{I}_{\mathrm{pc}}$ versus the square root of the scan rate. (c) Linear relationship between $\log \mathrm{I}_{\mathrm{pa}}$ and $\log \mathrm{I}_{\mathrm{pc}}$ versus the log scan rate for the CS-5-Ty electrode obtained by CV measurements. 
values of $\alpha$ (electron transfer coefficient) and $\mathrm{k}_{0}$ (electron transfer rate constant) were obtained by using the Tafel plot, which is presented in the inset of Figure S2 (SI section). The $(\alpha)$ value for catechol was calculated by inserting the slope of the Tafel plot in equation 5 (F: Faraday constant; $\mathrm{n}$ : electron transfer number; R: universal gases constant; $\mathrm{T}$ : absolute temperature).

slope $=\frac{(1-\alpha) n F}{2.3 R T}$

Considering the electron transfer number of $n=2$, the value of $\alpha$ was calculated to be 0.85 , showing that the activation free energy curve is not symmetrical and therefore is a quasi-reversible redox process. This result is typical when the $\mathrm{pH}$ is 7 , where the redox process involves two electrons and two $\mathrm{H}^{+} .{ }^{30,31}$ The $\mathrm{k}_{0}$ was obtained by equation 6 as follows:

$\mathrm{I}^{0}=\mathrm{nFA} \mathrm{k}_{0} \mathrm{C}$

where $\mathrm{I}^{0}$ is obtained from the Tafel plot $\left(\mathrm{I}^{0}=1.55 \times 10^{-5} \mathrm{~A}\right)$, $\mathrm{C}=3.85 \times 10^{-4} \mathrm{~mol} \mathrm{~L}^{-1}$, which is the concentration of catechol, F is the Faraday constant $(96485 \mathrm{C})$ and A the electroactive area of the electrode $\left(0.98 \mathrm{~cm}^{2}\right)$. The value of $\mathrm{k}_{0}$ was $2.13 \times 10^{-4} \mathrm{~cm} \mathrm{~s}^{-1}$. This value indicates that the electron transfer is comparable to values obtained for catechol using other electrodes. ${ }^{32}$

Figure $7 \mathrm{a}$ shows the voltammograms obtained at different concentrations of catechol in a range from 40 to $385 \mu \mathrm{mol} \mathrm{L}^{-1}$. Increase in both the anodic and cathodic peak currents can be observed, the anodic peak current being very intense, thus showing that catechol oxidation is favored in this electrode due to the presence of tyrosinase. In this wide concentration range, a linear response proportional to the catechol concentration was observed due to the increase of the anodic peak current in the system (inset Figure 7a). This result is expressed by equation 7 .

$\mathrm{I}_{\mathrm{pa}}(\mu \mathrm{A})=0.99( \pm 0.10)+284.20( \pm 0.40)[$ catechol] $\left(\mathrm{mmol} \mathrm{L}^{-1}\right)$ with $\mathrm{R}^{2}=0.998$

This electrode was also applied for the evaluation of dopamine and pyrogallol at different concentrations

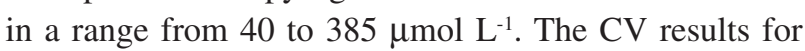
dopamine are shown in Figure 7b. In this case, an anodic peak varying between 0.13 and $0.18 \mathrm{~V}$ and a cathodic peak varying between -0.34 and $-0.38 \mathrm{~V}$ were observed, which corresponded to dopamine oxidation and reduction, respectively. In the inset of Figure 7b, a linear response of the anodic peak was observed as expressed by equation 8 .
$\mathrm{I}_{\mathrm{pa}}(\mu \mathrm{A})=-0.56( \pm 0.06)+140.7( \pm 0.3)$ [dopamine]

$\left(\mathrm{mmol} \mathrm{L}^{-1}\right)$ with $\mathrm{R}^{2}=0.996$

For the evaluation of pyrogallol, as shown in Figure 7c, the anodic peak potential corresponding to oxidation was observed at $0.08 \mathrm{~V}$. The cathodic peak was not observed. This behavior is related to the reactivity of $o$-quinones produced in the pyrogallol oxidation that can condense with other pyrogallol molecules producing purpurogallin, thus making the process irreversible..$^{33}$ In the inset of Figure $7 \mathrm{c}$, a linear response in a concentration range of 40 to $350 \mu \mathrm{mol} \mathrm{L}{ }^{-1}$ was also observed. The linear equation is expressed by equation 9 .

$\mathrm{I}_{\mathrm{pa}}(\mu \mathrm{A})=0.30( \pm 0.10)+165.26( \pm 1.9)[$ pyrogallol]

$\left(\mathrm{mmol} \mathrm{L}^{-1}\right)$ with $\mathrm{R}^{2}=0.996$

Table 3 shows the figures of merit of the electrode including the sensitivity and limit of detection compared to other electrodes already reported using tyrosinase. The sensitivities ( $\mathrm{S}$ ) were determined as the slope of the calibration curves and the detection limits (LOD) were calculated by the ratio $(3 \times \mathrm{SDb} / \mathrm{Slope})$, where $\mathrm{SDb}$ was the standard deviation of blank measurements $(n=10){ }^{33}$ It can be observed that the CS-5-Ty biosensor developed in this work presented the highest sensitivity for the three studied analytes compared to other sensors, and is most sensitive for catechol. It also presents the lowest detection limits for catechol and pyrogallol, and its detection limit for dopamine is comparable to the others. Additionally, the linear range found in the present work was larger than those reported. It is important to point out that it is well-known that tyrosinase is an unstable enzyme, and many efforts have been made to develop appropriate matrices to guarantee its operational stability in biosensors. ${ }^{11}$ Nevertheless, in the present work, the silica/titania chitosan composite afforded adequate characteristics for tyrosinase immobilization, thus assuring its sensitive response.

The electrodes were stored in a refrigerator at a temperature of approximately $5{ }^{\circ} \mathrm{C}$, for six months after which $\mathrm{CV}$ measurements were made to evaluate the catechol response. These results are shown in Figure S3 (SI section). It can be observed that after this period, the system still presents good performance confirming the activity of the tyrosinase enzyme. The CS-5 support electrode showed a lower response, similar to the original measures confirming the importance of the enzyme in the performance of the electrode. Chronoamperometric analysis was also performed after six months to evaluate the responses of the electrode CS-5-Ty for catechol, dopamine and pyrogallol. The chronoamperograms for each analyte 

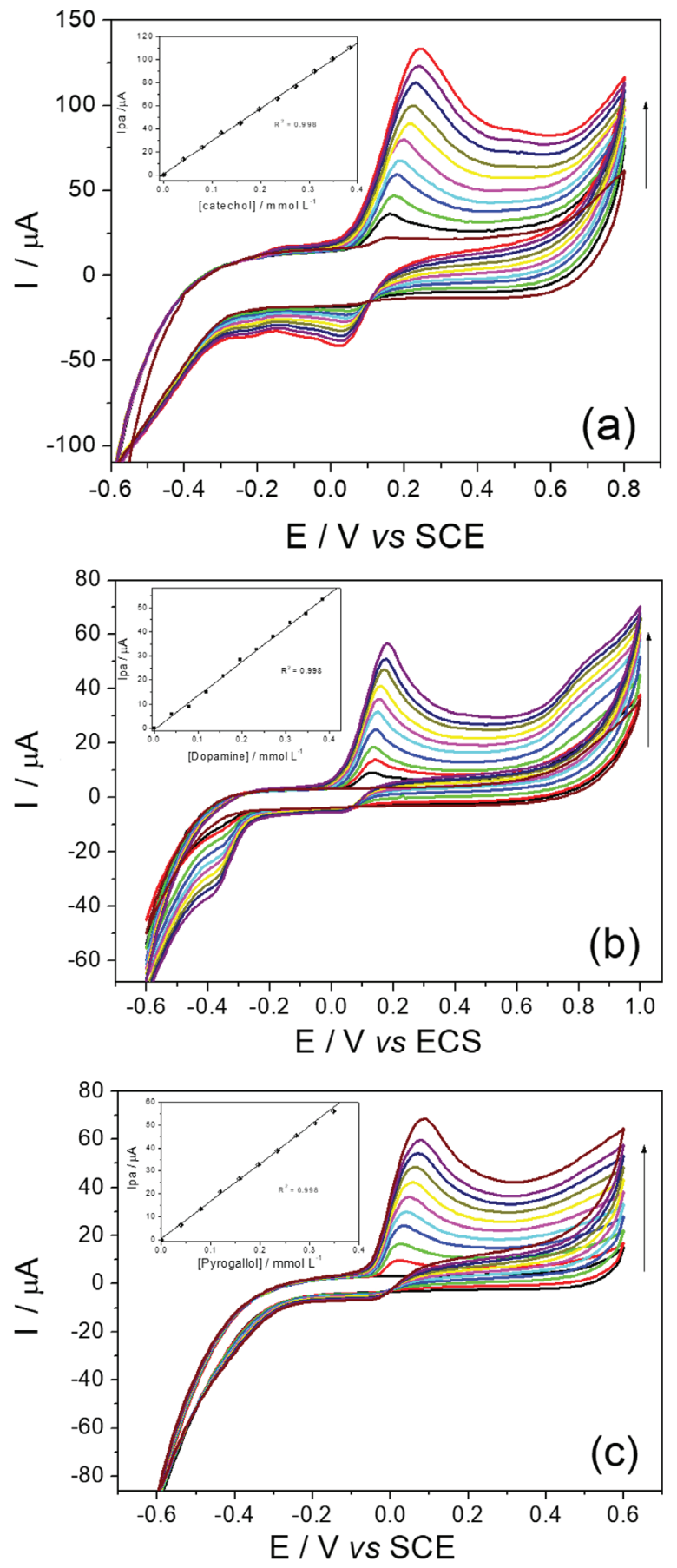

Figure 7. Cyclic voltammograms of the CS-5-Ty electrode in the presence of different concentrations (40-385 $\mu \mathrm{mol} \mathrm{L}^{-1}$ ) of: (a) cathecol, (b) dopamine and (c) pyrogallol in phosphate buffer solution $(\mathrm{pH} 7)$ and $0.1 \mathrm{~mol} \mathrm{~L}^{-1}$ $\mathrm{KCl}$ at $20 \mathrm{mV} \mathrm{s}^{-1}$. Inset figure: linear relationship obtained by $\mathrm{CV}$ analysis for different concentrations of analytes versus the anodic peak current.

at different concentrations are shown in Figure 8a. In Figure $8 \mathrm{~b}$, a linear response proportional to the analyte concentration due to an increase of the anodic current in the system was observed. The equations obtained are presented in the SI section: for catechol equation S3, for dopamine equation S4 and for pyrogallol equation S5.
We can observe that even after this time, the system still presents good sensitivity and low detection limits of $3.38 \mu \mathrm{mol} \mathrm{L}-1$ for catechol, $1.16 \mu \mathrm{mol} \mathrm{L}^{-1}$ for dopamine and $8.47 \mu \mathrm{mol} \mathrm{L}^{-1}$ for pyrogallol for the three analytes when compared to the results shown in Table 3. Although there was a reduction in the parameters of the electrodes after the six month-period, these values are close to those already reported, ${ }^{10,34-39}$ thus indicating that some of the active sites of tyrosinase were still available after this time. It can be inferred that the mesoporous electrode formed by the silica/ titania material containing chitosan provides adequate stability to the tyrosinase enzyme.

Aiming to evaluate the kinetic behavior of the tyrosinase enzyme in the CS-5-Ty electrode, the apparent MichaelisMenten constant $\left(\mathrm{K}_{\mathrm{M}}^{\mathrm{app}}\right)$ was calculated for catechol using Lineweaver-Burk plots ${ }^{40}$ (Figure S4, SI section). The value obtained was $242 \mu \mathrm{mol} \mathrm{L}{ }^{-1}$. This value demonstrated that the immobilized tyrosinase presented better enzymatic activity than the free enzyme, which was reported as $300 \mu \mathrm{mol} \mathrm{L}^{-1},{ }^{41}$ and exhibited significant affinity towards catechol, with values comparable to those found in the literature for immobilized tyrosinase enzyme. For example, the values

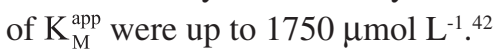

The CS-5-Ty electrode presented good repeatability for all analytes. Nine determinations were performed using one same electrode for each analyte. For catechol, dopamine and pyrogallol by cyclic voltammetry at an analyte concentration of $0.350 \mathrm{mmol} \mathrm{L}^{-1}$, resulting in relative standard deviations of $2.0 \%$ for catechol, $4.8 \%$ for dopamine and $7.7 \%$ for pyrogallol. The electrochemical response for this electrode is shown in the SI section, Figure S5. The reproducibility was also evaluated for three electrodes using a $0.350 \mathrm{mmol} \mathrm{L}^{-1}$ catechol solution, resulting in a relative standard deviation of $8 \%$.

An interference study was performed by chronoamperometry for the three analytes starting from $0.20 \mathrm{mmol} \mathrm{L}^{-1}$ of each analyte. The interferents were added in a 1:0.5 ratio of analyte:interferent. For catechol, no interference was observed for citric acid, glucose and caffeine, as the current increase was insignificant, which can be seen in Figure S6a (SI section). For dopamine, no interference was observed for caffeine and citric acid, however, increases in the current of nearly $30 \%$ were observed for uric acid and glucose (Figure S6b). For pyrogallol, no interference was observed for citric acid, caffeine and glucose, however, for ascorbic acid a current increase of nearly $15 \%$ was observed in Figure S6c (SI section).

These results indicate that this electrode is very promising to be applied as a catechol, dopamine and pyrogallol sensor. We believe that the overall performance of this electrode is related to the operative and stable conditions of the enzyme 
Table 3. Performances of the CS-5-Ty biosensor and other sensors that use the tyrosinase enzyme for catechol, dopamine and pyrogallol oxidation

\begin{tabular}{|c|c|c|c|c|c|}
\hline Modified electrode & Analyte & $\begin{array}{l}\text { Sensitivity / } \\
(\mu \mathrm{A} / \mu \mathrm{M})\end{array}$ & $\begin{array}{c}\text { Linear range / } \\
\left(\mu \mathrm{mol} \mathrm{L} \mathrm{L}^{-1}\right)\end{array}$ & $\begin{array}{c}\text { LOD / } \\
\left.(\mu \mathrm{mol} \mathrm{L})^{-1}\right)\end{array}$ & Reference \\
\hline Ty-CoPc-CNTP & catechol & 0.064 & $10-120$ & 1.66 & 34 \\
\hline Tyrosinase-modified BDND & catechol & 0.096 & $5-120$ & 3.28 & 35 \\
\hline Glassy carbon GO/MWNT/Ty & catechol & ca. 0.120 & - & 0.50 & 10 \\
\hline CS-5-Ty & catechol & 0.284 & $40-385$ & 0.83 & this work \\
\hline Au-MEA/PEDOT-Ty & dopamine & 0.002 & $20-300$ & 0.24 & 36 \\
\hline Tyrosinase/NiO/ITO & dopamine & 0.06 & $2-100$ & 1.04 & 37 \\
\hline PEDOT-Ty & dopamine & - & $10-150$ & 0.99 & 38 \\
\hline Glassy carbon GO/MWNT/Ty & dopamine & ca. 0.029 & - & 1.70 & 10 \\
\hline CS-5-Ty & dopamine & 0.141 & $40-385$ & 1.50 & this work \\
\hline Glassy carbon GO/MWNT/Ty & pyrogallol & ca. 0.02 & - & 2.0 & 10 \\
\hline CS-5-Ty & pyrogallol & 0.165 & $40-385$ & 0.84 & this work \\
\hline
\end{tabular}

Ty-CoPc-CNTP: tyrosinase copper(II) phthalocyanine carbon nanotubes paste electrode; BDND: boron-doped nanocrystalline diamond; GO/MWNT/Ty: graphene oxide/multi-walled carbon nanotube/tyrosinase; Au-MEA/PEDOT-Ty: gold microelectrode arrays/poly(3,4-ethylenedioxythiophene) tyrosinase; ITO: indium tin oxide.
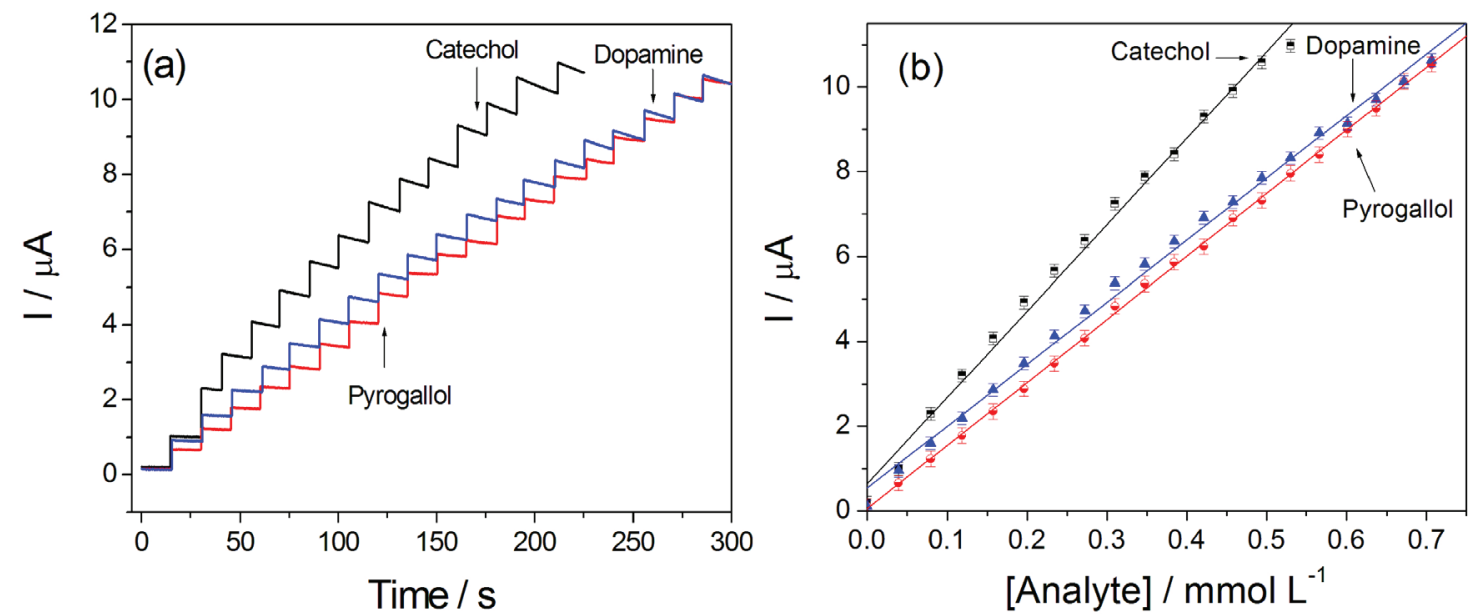

Figure 8. (a) Chronoamperometric response (I vs. time) for the CS-5-Ty electrode with successive additions of the phenolic compounds in the concentration range of 0.0 to $0.8 \mathrm{mmol} \mathrm{L}^{-1}$, obtained after a six month-storage period. (b) Linear relationships between the current intensity and concentrations of catechol, pyrogallol and dopamine.

in the matrix, thus maintaining available the active sites. These conditions are given by the pore system, with size and amount adequate to immobilize macromolecules, such as chitosan that present ideal chemical conditions for enzyme immobilization. After chitosan immobilization, the matrix still maintains the porosity for enzyme immobilization, which maintains available the active sites. Additionally, this system, with all these physicochemical properties, presents potential for the immobilization of other enzymes, maintaining their operational stability and enlarging the possibilities of application.

\section{Conclusions}

Conductive silica/titania graphite composite with planned chemical and textural properties, showing pore diameters between 10 and $30 \mathrm{~nm}$, was prepared. These properties allowed the functionalization with chitosan and then the immobilization of tyrosinase. The enzyme was shown to be operative and stable in this composite, permitting the development of a highly sensitive and reproducible carbon ceramic electrode for phenolic compounds. It can be explained that the redox process for catechol in the electrode presented a diffusional behavior, suggesting that the silica/titania surface is covered by chitosan. Additionally, it was observed that even after six months, the electrodes still presented a good response, and the limits of detection are low for the three analytes (3.38 $\mu \mathrm{mol} \mathrm{L}^{-1}$ for catechol, $1.16 \mu \mathrm{mol} \mathrm{L}^{-1}$ for dopamine and $8.47 \mu \mathrm{mol} \mathrm{L}^{-1}$ for pyrogallol). The apparent MichaelisMenten constant was calculated for catechol, and the value obtained was $242 \mu \mathrm{mol} \mathrm{L}^{-1}$, showing that the immobilized tyrosinase presented an enzymatic activity better than the free enzyme, with a value of $300 \mu \mathrm{mol} \mathrm{L}^{-1}$. 
Considering the textural, morphological and chemical characteristics of the electrode that provided stability and operability for the tyrosinase enzyme, this system presents an excellent support to immobilize other enzymes or macromolecules as biological markers, thus enlarging the possibilities of applications.

\section{Supplementary Information}

Supplementary information (data from TGA, Nyquist diagram, CV, chronoamperograms, amperograms and equations) are available free of charge at http://jbcs.sbq.org.br as a PDF file.

\section{Acknowledgments}

The authors are grateful to CNPQ (Conselho Nacional de Desenvolvimento Científico e Tecnológico), FAPERGS (Fundação de Amparo à Pesquisa do Estado do Rio Grande do Sul), and CAPES (Coordenação de Aperfeiçoamento Pessoal de Nível Superior) for financial support and fellowships.

\section{References}

1. Kanamori, T.; Funatsu, T.; Tsunoda, M.; Analyst 2016, 141, 2568.

2. Figueiredo, E. C.; Tarley, C. R. T.; Kubota, L. T.; Rath, S.; Arruda, M. A. Z.; Microchem. J. 2007, 85, 290.

3. Pisoschi, A. M.; Cimpeanu, C.; Predoi, G.; Open Chem. 2015, 13,824 .

4. Ramos, J. V. H.; Morawski, F. M.; Costa, T. M. H.; Dias, S. L. P.; Benvenutti, E. V.; Menezes, E. W.; Arenas, L. T.; Microporous Mesoporous Mater. 2015, 217, 109.

5. Manasa, G.; Mascarenhas, R. J.; Satpati, A. K.; D’Souza, O. J.; Dhason, A.; Mater. Sci. Eng., C 2017, 73, 552.

6. Rahman, M. M.; Balkhoyor, H. B.; Asiri, A. M.; J. Environ. Manage. 2017, 188, 228.

7. Kirsch, N.; Honeychurch, K. C.; Hart, J. P.; Whitcombe, M. J.; Electroanalysis 2005, 17, 571.

8. Haghighi, B.; Rahmati-Panah, A.; Shleev, S.; Gorton, L.; Electroanalysis 2007, 19, 907.

9. Wang, G.; Xu, J.-J.; Ye, L.-H.; Zhu, J.-J.; Chen, H.-Y.; Bioelectrochemistry 2002, 57, 33.

10. Vlamidis, Y.; Gualandi, I.; Tonelli D.; J. Electroanal. Chem. 2017, 799, 285.

11. Lupu, S.; Lete, C.; Balaure, P. C.; Caval, D. I.; Mihailciuc, C.; Lakard, B.; Hihn, J.-Y.; Campo, F. J. D.; Sensors 2013, 13, 6759.

12. Caldas, E. M.; Novatzky, D.; Deon, M.; Menezes, E. W.; Hertz, P. F.; Costa, T. M. H.; Arenas, L. T.; Benvenutti, E. V.; Microporous Mesoporous Mater. 2017, 247, 95.
13. Roushani, M.; Karami, M.; Dizajdizi, B. Z.; Microchim. Acta 2017, 184, 473.

14. Maroneze, C. M.; Luz, R. C. S.; Landers, R.; Gushikem, Y.; J. Solid State Electrochem. 2010, 14, 115.

15. Maroneze, C. M.; Arenas, L. T.; Luz, R. C. S.; Benvenutti, E. V.; Landers, R.; Gushikem, Y.; Electrochim. Acta 2008, 53, 4167.

16. Ennajih, H.; Bouhfid, R.; Essassi, E. M.; Bousmina, M.; Kadib, A. E.; Microporous Mesoporous Mater. 2012, 152, 208.

17. Dong, W.; Han, J.; Shi, J.; Liang, W.; Zhang, Y.; Dong C.; Chin. J. Chem. 2017, 35, 1305.

18. Zaia, D. A. M.; Zaia, C. T. B. V.; Lichtig, J.; Quim. Nova 1998, $21,787$.

19. Gregg, S. J.; Sing, K. S. W.; Adsorption, Surface Area and Porosity; Academic Press: London, 1982.

20. Greef, R.; Peat, R.; Peter, L. M.; Pletcher, D.; Robinson, J.; Instrumental Methods in Electrochemistry; John Wiley \& Sons, Inc.: New York, 1985.

21. Klymenko, O. V.; Evans, R. G.; Hardacre, C.; Svir, I. B.; Compton, R. G.; J. Electroanal. Chem. 2004, 571, 211.

22. Brownson, D. A. C.; Banks, C. E.; The Handbook of Graphene Electrochemistry; Springer-Verlag London Ltd.: London, 2014.

23. Menezes, E. W.; Nunes, M. R.; Arenas, L. T.; Dias, S. L. P.; Garcia, I. T. S.; Gushikem, Y.; Costa, T. M. H.; Benvenutti, E. V.; J. Solid State Electrochem. 2012, 16, 3703.

24. Murphy-Pérez, E.; Arya, S. K.; Bhansali, S.; Analyst 2011, 136, 1686.

25. Durán, N.; Rosa, M. A.; D’Annibale, A.; Gianfreda, L.; Enzyme Microb. Technol. 2002, 31, 907.

26. Vicentini, F. C.; Janegitz, B. C.; Brett, C. M. A.; Fatibello-Filho, O.; Sens. Actuators, B 2013, 188, 1101.

27. Zang, J. B.; Wang, Y. H.; Zhao, S. Z.; Bian, L. Y.; Lu, J.; Diamond Relat. Mater. 2007, 16, 16.

28. Morawski, F. M.; Deon, M.; Nicolodi, S.; Menezes, E. W.; Costa, T. M. H.; Dias, S. L. P.; Benvenutti, E. V.; Arenas, L. T.; Electrochim. Acta 2018, 264, 319.

29. Yuan, S.; Hu, S.; Electrochim. Acta 2004, 49, 4287.

30. Lin, Q.; Li, Q.; Batchelor-McAuley, C.; Compton, R. G.; J. Phys. Chem. C 2015, 119, 1489.

31. Wang, J.; Analytical Electrochemistry;Wiley-VCH: New York, 2001.

32. Ojani, R.; Raoof, J.-B.; Hosseinzadeh, R.; Alinezhad, A.; Monatsch Chem. 2009, 140, 503.

33. Apetrei, C.; Alessio, P.; Constantino, C. J. L.; Sajac, J. A.; Rodriguez-Mendez, M. L.; Pavinatto, F. J.; Fernandes, E. G. R.; Zucolotto, V.; Oliveira Jr., O. N.; Biosens. Bioelectron. 2011, 26, 2513.

34. Apetrei, I. M.; Rodriguez-Mendez, M. L.; Apetrei, C.; de Saja, J. A.; Sens. Actuators, B 2013, 177, 138.

35. Zou, Y. S.; Lou, D.; Dou, K.; He, L. L.; Dong, Y. H.; Wang, S. L.; J. Solid State Electrochem. 2016, $20,47$. 
36. Lete, C.; Lakard, B.; Hihn, J. Y.; del Campo, F. J.; Lupu, S.; Sens. Actuators, B 2017, 240, 801.

37. Roychoudhury, A.; Basu, S.; Jha, S. K.; Biosens. Bioelectron. 2016, 84, 72.

38. Lupu, S.; Lete, C.; Balaure, P. C.; del Campo, F. J.; Munõz, F. X.; Lakard, B.; Hihn, J.-Y.; Sens. Actuators, B 2013, 181, 136.

39. Tembe, S.; Kubal, B. S.; Karve, M.; D’Souza, S. F.; Anal. Chim. Acta 2008, 612, 212.

40. Jedrzak, A.; Rebi, T.; Klapiszewski, L.; Zdarta, J.; Milczarek, G.; Jesionowski, T.; Sens. Actuators, B 2018, 256, 176.
41. Espín, J. C.; Varón, R.; Fenoll, L. G.; Gilabert, M. A.; GarcíaRuíz, P. A.; Tudela, J.; Garcia-Cánovas, F.; Eur. J. Biochem. 2000, 267, 1270.

42. Chen, L.; Gu, B.; Zhu, G.; Wu, Y.; Liu, S.; Xu, C.; J. Electroanal. Chem. 2008, 617, 7.

Submitted: May 9, 2019

Published online: August 12, 2019 